\title{
DETECÇÃO E CLASSIFICAÇÃO DE FALTAS A PARTIR DA ANÁLISE DE REGISTROS OSCILOGRÁFICOS VIA REDES NEURAIS ARTIFICIAIS E TRANSFORMADA WAVELET
}

\author{
Kleber Melo e Silva* \\ kms@ee.ufcg.edu.br \\ Núbia Silva Dantas Brito* \\ nubia@ee.ufcg.edu.br \\ Flávio Bezerra Costa* \\ flabclee.ufcg.edu.br
}

\author{
Benemar Alencar de Souza* \\ benemardee.ufcg.edu.br
}
Karcius Marcelus Colaço Dantas*
karciusdee.ufcg.edu.br

Sandra Sayonara Bispo da Silva ${ }^{\dagger}$

sandrasechesf.gov.br

*Universidade Federal de Campina Grande - CEEI/UAEE/GSE

Av. Aprígio Veloso 882, Bodocongó, 58109-970 Campina Grande - Brasil

${ }^{\dagger}$ Companhia Hidro Elétrica do São Francisco - DA/STI/DSI

R. Quinze de Março 50, Bongi, 58761-901 Recife - Brasil

\section{RESUMO}

Este artigo apresenta um método de detecção e classificação de faltas em linhas de transmissão, a partir da análise de registros oscilográficos via redes neurais artificiais e transformada wavelet. Realiza-se a detecção da falta e a determinação de sua duração através de um conjunto de regras heurísticas construídas a partir da análise dos sinais de corrente nos domínios do tempo e wavelet. O método diferencia faltas de outras ocorrências relacionadas à qualidade da energia elétrica, tais como afundamentos de tensão e transitórios de chaveamento. Uma rede neural classifica faltas a partir do reconhecimento dos padrões das tensões e correntes relacionados a cada tipo específico. O método proposto foi avaliado para registros simulados e reais em linhas de transmissão do sistema Chesf, apresentando bons resultados em ambos os casos.

\footnotetext{
ARTIGO CONVIDADO: Artigo submetido em 31/05/2006

1a. Revisão em 01/09/2006

2a. Revisão em 30/10/2006

Aceito sob recomendação do Editor Convidado
}

Versão completa e revisada de artigo apresentado no SBAI-2005

Prof. Osvaldo Ronald Saavedra Mendez
PALAVRAS CHAVES: Redes neurais artificiais, transformada wavelet, detecção e classificação de faltas em linhas de transmissão.

\section{ABSTRACT}

This paper presents a method for fault detection and classification in transmission lines, based on analysis of oscillographic data using artificial neural networks and wavelet transform. The fault detection and its clearing time are determined based on a set of heuristic rules obtained from the current waveform analysis in time and wavelet domains. The method is able to single out faults from other power quality disturbances such as voltage sags and oscillatory transients, which are common in power systems operation. An ANN classifies the fault by the voltage and current waveforms pattern recognition in time domain. The method was used for fault detection and classification from both simulated and real oscillographic data of Chesf, a Brazilian utility company, with excellent results.

KEYWORDS: Artificial neural networks, wavelet transform, fault detection and classification in transmission lines. 


\section{INTRODUÇÃO}

As faltas em sistemas de potência acarretam desligamentos não programados de seus componentes. Sua extinção deve ser feita de forma rápida e apropriada pelos equipamentos de proteção, desativando apenas a parte defeituosa do sistema.

Após a eliminação de uma falta, uma análise mais detalhada é imprescindível para a avaliação do desempenho do sistema de proteção. Nesse momento, destaca-se a importância da oscilografia, que consiste do constante monitoramento das grandezas elétricas do sistema de potência e do estado de operação do sistema de proteção. O equipamento empregado atualmente nesse monitoramento é denominado registrador digital de perturbação (RDP). Ele possui recursos de armazenamento e transferência de dados via rede WAN (wide area network), possibilitando a concepção de redes de monitoramento de grande porte, denominadas convenientemente de redes oscilográficas.

As redes oscilográficas geralmente possuem um sistema de verificação e coleta das informações registradas pelos RDPs (Kezunovic and Rikalo, 1999). Essas informações são coletadas automaticamente e organizadas em registros padronizados (IEEE Power System Relaying Committee, 1999). Em seguida, são transferidas para o servidor central da oscilografia, onde são armazenadas e, posteriormente, compartilhadas na rede corporativa da empresa (figura 1 ).

A tecnologia atual permite a concepção de RDPs com altas taxas de amostragem, capturando, além de faltas, eventos relacionados à qualidade da energia elétrica (QEE). Em contrapartida, pode-se provocar problemas relacionados ao armazenamento de uma grande quantidade de informações que não estão relacionadas a uma falta. Na verdade, na maioria das vezes, os RDPs são ativados de forma indevida por distúrbios relacionados à QEE, como manobras de chaveamento, afundamentos de tensão ou por operações de manutenção do sistema.

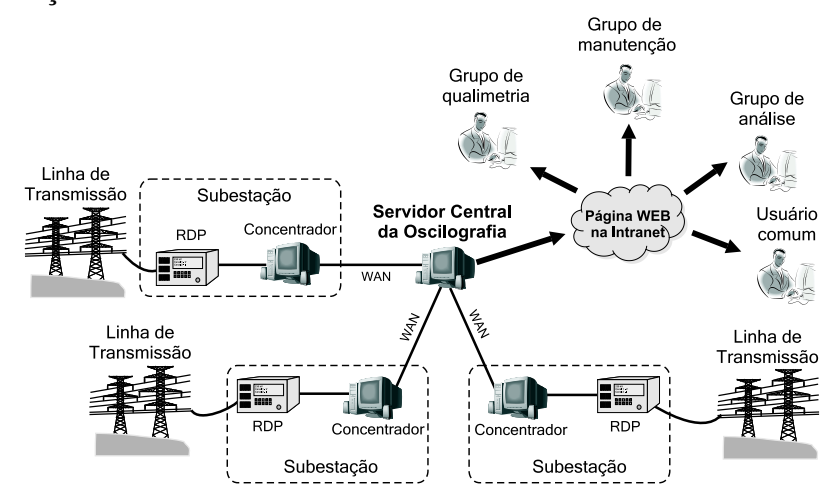

Figura 1: Representação do processo de coleta automática de registros adquiridos pelos RDPs.
Uma depuração prévia dos registros adquiridos pelos RDPs se faz necessária. De fato, algoritmos para o diagnóstico de faltas devem ser empregados para identificar os registros de faltas e permitir que apenas esses sejam transferidos para o servidor central da oscilografia.

Em relação à etapa de detecção da falta, vários algoritmos utilizando redes neurais artificiais (RNAs) vêm sendo propostos (Kezunovic and Rikalo, 1996; Oleskovicz et al., 2003; Mahanty and Gupta, 2004). Por outro lado, a transformada wavelet (TW) também vem sendo largamente empregada, devido a sua aplicabilidade na análise de sinais não estacionários, a exemplo dos sinais transitórios oriundos de faltas e distúrbios de QEE (Solanki et al., 2001; Kim and Aggarwal, 2001). No entanto, esses métodos distinguem a falta apenas da situação normal de operação em regime permanente do sistema, não contemplando as demais situações de operação que podem ser registradas pelos RDPs.

A maioria das publicações relacionadas à classificação de faltas utilizam as RNAs (Oleskovicz et al., 2003; Mahanty and Gupta, 2004; Souza et al., 2004b). Por outro lado, técnicas como a TW também foram utilizadas para estabelecer regras de classificação de faltas (Youssef, 2001). Alternativamente, têm sido propostos algoritmos que combinam técnicas de inteligência artificial e de processamento digital de sinais, por exemplo: TW e RNA (Kashyap and Shenoy, 2003); lógica fuzzy e RNA (Vasilic and Kezunovic, 2002); TW e lógica fuzzy (Youssef, 2004; Pradhan et al., 2004). Entretanto, na maioria dos casos, apenas faltas simuladas com softwares do tipo EMTP (Electromagnetic Transient Program) são avaliadas, não contemplando-se faltas reais.

Nesse artigo, apresenta-se um algoritmo para detecção e classificação de faltas em linhas de transmissão (LTs) através da análise de registros oscilográficos via RNA e TW. A detecção da falta e sua duração é realizada através da análise dos sinais de corrente nos domínios do tempo e wavelet. Nessa etapa, uma falta é diferenciada de outras situações relacionadas à QEE. Por fim, a classificação da falta é feita por uma RNA, cujos sinais de entrada são as tensões e correntes na LT no domínio do tempo.

Um software de análise de registros oscilográficos foi desenvolvido baseado no método proposto. Ele resultou de um projeto de P\&D da Chesf, desenvolvido pelo Grupo de Sistemas Elétricos da Universidade Federal de Campina Grande. O software encontra-se implantado, em escala piloto, no concentrador da subestação (SE) Campina Grande II (CGD), realizando a análise dos registros da LT 04V4 de $230 \mathrm{kV}$ e 188 $\mathrm{km}$, localizada entre as SEs CGD e Natal II (NTD), pertencentes ao subsistema Leste da Chesf. 


\section{MÉTODO PROPOSTO}

O método está dividido basicamente em dois módulos: detecção e classificação da falta (figura 2).

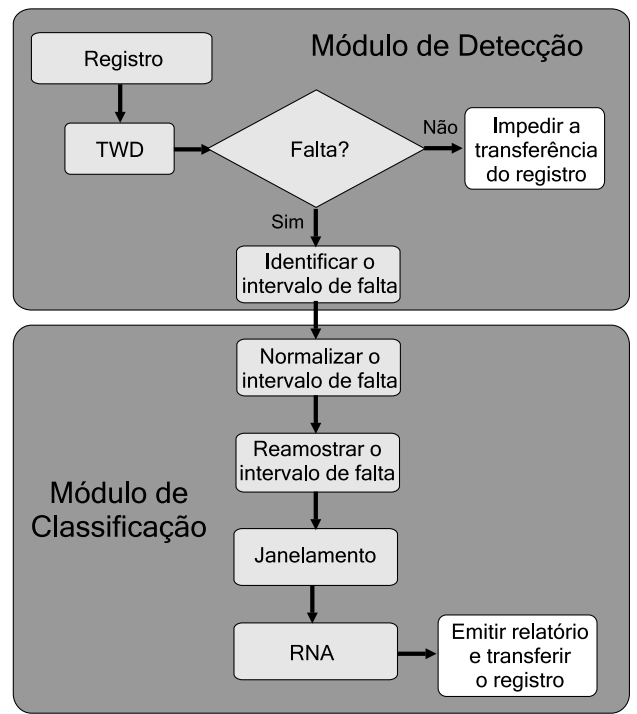

Figura 2: Diagrama de blocos do método proposto.

Inicialmente, no módulo de detecção, as tensões e correntes de um registro são obtidas. Em seguida, aplica-se a transformada wavelet discreta (TWD) apenas às correntes, obtendose os coeficientes wavelet da primeira escala de resolução. Avalia-se, então, um conjunto de regras para identificar se o registro corresponde a uma falta. Caso nenhuma falta seja detectada, o algoritmo é finalizado e a transferência do registro até o servidor central é evitada. Entretanto, se uma falta for detectada, seus instantes inicial e final são identificados, a partir de um segundo conjunto de regras.

No módulo de classificação, as amostras de tensão e corrente, referentes ao intervalo de falta delimitado na fase de detecção, são normalizadas pelos seus respectivos valores máximos no registro. Em seguida, realiza-se a reamostragem desses sinais convertendo-os da freqüência de amostragem original do RDP para a freqüência padrão de $1200 \mathrm{~Hz}$. Um processo de janelamento é empregado ao intervalo de falta, já normalizado e reamostrado, e cada janela de amostras é apresentada a uma RNA, que indicará qual é o tipo de falta relacionado àquelas amostras. $\mathrm{O}$ tipo de falta mais identificado a RNA, após a avaliação de todas as janelas de amostras, é o que prevalece e o que constará no relatório de saída.

\subsection{Módulo de Detecção}

As regras para a detecção da falta e de seu intervalo de duração foram criadas a partir da observação do comportamento dos sinais de correntes reais em diversas situações de operação do sistema.

\subsubsection{Regras de Detecção da Falta}

Para a extração das regras foram considerados apenas os coeficientes wavelet de detalhe referentes a primeira escala de resolução, sendo a wavelet Daubechies 4 empregada para o cálculo da TWD (Daubechies, 1992).

A detecção feita apenas pela avaliação das correntes no domínio wavelet pode falhar em algumas situações, como é o caso de afundamentos de tensão e energizações de LTs. Nestes casos, o máximo coeficiente wavelet da primeira escala pode ser da mesma ordem de grandeza que o de uma falta. Para afundamentos de tensão, a incidência de componentes de alta freqüência é maior para registros capturados em LTs próximas à LT com falta, enquanto que para energizações é maior dependendo das condições de operação do sistema. No entanto, ao avaliar o comportamento das correntes no início e no fim do registro, pode-se identificar esses distúrbios. Dessa forma, as correntes devem ser analisadas nos domínios do tempo e wavelet (Silva, 2005).

As regras utilizadas para a detecção da falta são as seguintes:

1. Se $C_{\max }<C^{*}$, então não é um registro de uma falta.

2. Se $C_{\max } \geqslant C^{*}, I_{\text {pre }}<0,2 I_{\text {pos }}$ e $I_{\text {pos }}>I_{m}$, então não é um registro de uma falta.

3. Se $C_{\max } \geqslant C^{*} \mathrm{e}\left|I_{\text {pre }}-I_{\text {pos }}\right|<0,5 \max \left\{I_{\text {pre }}, I_{\text {pos }}\right\}$, então não é um registro de uma falta.

4. Se $C_{\max } \geqslant C^{*}$ e se as demais regras não foram satisfeitas, então o registro corresponde a uma falta.

Sendo $C_{\max }$ o máximo valor absoluto dos coeficientes wavelet da primeira escala das correntes; $C^{*}$ um limiar estabelecido a partir da observação dos coeficientes wavelet das correntes para diversos registros reais; $I_{\text {pre }}$ e $I_{\text {pos }}$, respectivamente, os valores de pico das correntes no primeiro e no último ciclo registrado; $I_{m}$ um limiar estabelecido de acordo com a corrente de carga típica no sistema.

De um modo geral, não é possível associar uma das regras a um distúrbio específico. De fato, há uma interseção entre elas, de modo que um tipo de distúrbio pode satisfazer a mais de uma regra, como por exemplo, um afundamento de tensão pode satisfazer as regras um e três, enquanto que uma energização de LT pode ser relacionada às regras um e dois. No entanto, como elas são avaliadas na sequiência apresentada, se tornam excludentes.

\subsubsection{Regras de Identificação da Duração da Falta}

De um modo geral, um registro correspondente a uma falta apresenta três situações nas quais os sinais de tensão e corrente se comportam distintamente: as etapas de pré-falta, falta e pós-falta (figura 3). 


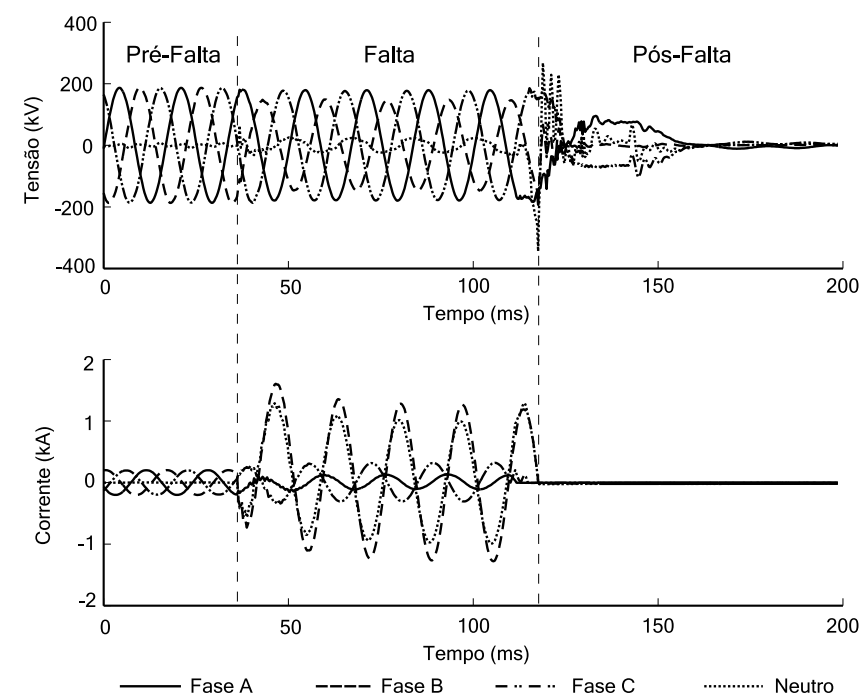

Figura 3: Registro de uma falta real do tipo BT com a indicação das etapas de pré-falta, falta e pós-falta.

A etapa de pré-falta consiste no intervalo de tempo no qual o sistema está em operação normal. A segunda etapa consiste dos sinais de tensão e corrente do sistema em situação de falta. Por fim, a etapa de pós-falta refere-se ao comportamento do sistema após a atuação da proteção.

A determinação da duração da falta é feita através da análise dos coeficientes wavelets das correntes de fase e de neutro na primeira escala de resolução da TWD. A corrente de neutro é um importante indicativo do envolvimento da terra na falta (Silva, 2005).

Primeiramente, os coeficientes wavelet são filtrados empregando-se a técnica de hard wavelet threshold (Burrus et al., 1998):

$$
c_{k}=\left\{\begin{array}{l}
c_{k}, \text { se }\left|c_{k}\right| \geqslant 0,1 C_{\max } \\
0, \text { caso contrário }
\end{array},\right.
$$

sendo $c_{k}$ o $k$-ésimo coeficiente wavelet e $C_{\max }$ o maior coeficiente wavelet em valor absoluto. Logo, o seguinte algoritmo é avaliado para determinar as amostras inicial e final do intervalo de falta:

1. Identificar o índice do primeiro coeficiente diferente de zero para cada uma das correntes de fase e de neutro.

2. O índice do coeficiente inicial da falta é definido como o maior índice dentre os determinados no passo 1.

3. Identificar o índice do último coeficiente diferente de zero para cada uma das correntes de fase.

4. O índice do coeficiente final da falta é definido como o maior índice dentre os determinados no passo 3.
5. Identificar o índice do último coeficiente diferente de zero para a corrente de neutro.

6. Se o índice obtido no passo 4 for maior que o obtido no 5 , então o índice do coeficiente final da falta passa a ser o determinado no passo 5 .

7. As amostras inicial e final da falta são determinadas, respectivamente, como o dobro do índice dos coeficientes inicial e final da falta (processo de sobreamostragem) (Burrus et al., 1998).

Na figura 4 são apresentados os coeficientes wavelet filtrados das correntes da figura 3. Nesse caso, os instantes inicial e final da falta foram determinados como sendo $36,2 \mathrm{~ms}$ e $117,5 \mathrm{~ms}$, avaliando-se os coeficientes da corrente na fase B.

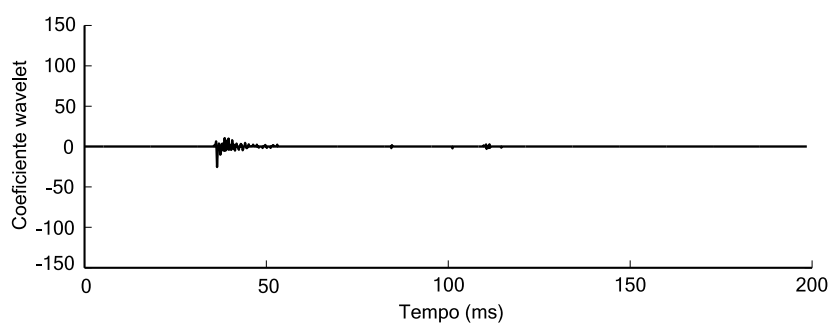

(a)

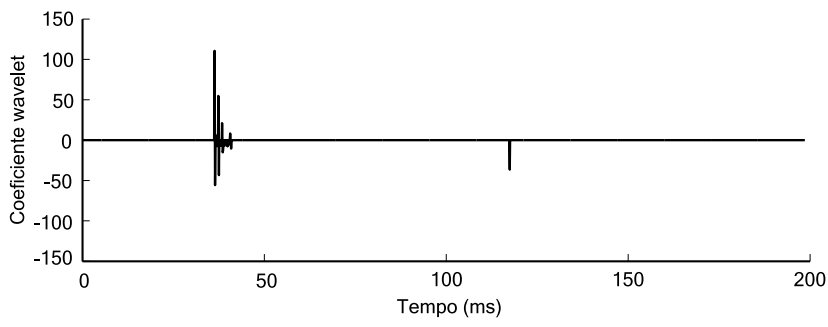

(b)

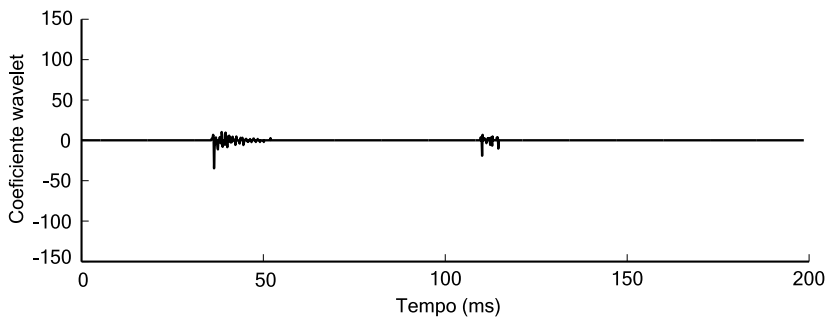

(c)

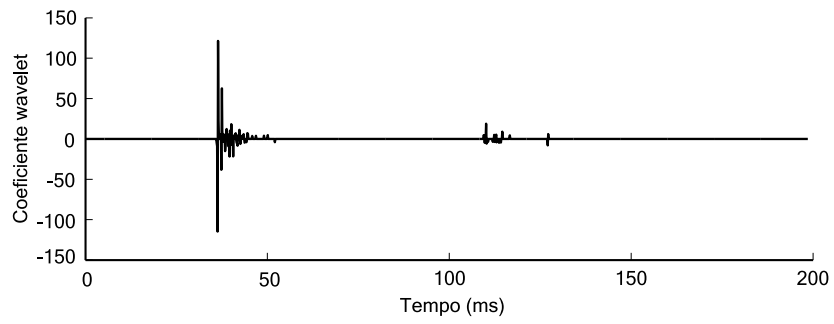

(d)

Figura 4: Coeficientes wavelet filtrados das correntes da figura 3: (a) fase A; (b) fase B; (c) fase C; (d) neutro. 


\subsection{Módulo de Classifi cação}

O módulo de classificação é divido em quatro etapas: normalização, reamostragem, janelamento e classificação.

\subsubsection{Normalização}

As amostras das tensões e correntes no domínio do tempo, referentes ao intervalo de falta, são normalizadas pelos respectivos valores máximos encontrados no registro. Dessa forma, os padrões de entrada da RNA oriundos de faltas simuladas e reais são uniformizados, mesmo quando provenientes de níveis de tensão diferentes.

\subsubsection{Reamostragem}

As características relevantes para a classificação de faltas estão presentes, principalmente, nas componentes de baixa freqüência dos sinais de tensão e corrente (Neves et al., 2004). No entanto, a maioria dos RDPs empregados atualmente possuem taxas de amostragem típicas da ordem de $15360 \mathrm{~Hz}$, sendo capazes de capturar freqüências, que de fato podem dificultar a classificação a partir da RNA (Silva, 2005). Dessa forma, implementou-se uma etapa de reamostragem dos sinais.

A reamostragem é aplicada aos sinais de tensão e corrente, referentes apenas ao intervalo de falta delimitado. Ela consiste na conversão da frequiência de amostragem original (freqüência do RDP) para uma freqüência padrão. Como $1200 \mathrm{~Hz}$ é a menor freqüência de amostragem dos RDPs da Chesf, ela foi escolhida como freqüência padrão.

\subsubsection{Janelamento}

O processo de janelamento consistiu no agrupamento de 5 amostras (1/4 de ciclo para a freqüência de amostragem de $1200 \mathrm{~Hz}$ ) consecutivas das tensões e correntes (de fase e de neutro) num único padrão de entrada da RNA. Cada padrão tem 40 entradas ([4 tensões +4 correntes $]$ x 5 amostras). A janela de dados percorre as amostras dos sinais referentes ao intervalo de falta delimitado, deslocando-se ao passo de uma amostra (Souza et al., 2004b).

\subsubsection{Classificação}

Nessa etapa, cada janela obtida no processo de janelamento é apresentada a uma RNA do tipo perceptron de múltiplas camadas (MLP), que deve identificar o tipo de falta correspondente àquelas amostras. $\mathrm{O}$ processo consiste, basicamente, em verificar o tipo mais indicado pela RNA ao avaliar todas as janelas. Essa estratégia garante que, mesmo que a RNA cometa erros, na grande maioria das vezes a classificação da falta no registro é correta.
Para treinar a RNA é necessário um conjunto de sinais de tensão e corrente referentes a uma grande variedade de situações de faltas. Como essa diversidade não é encontrada em registros reais, casos de faltas simuladas são comumente utilizados. Com essa estratégia se tenta fazer com que a RNA consiga classificar corretamente as situações simuladas e reais.

Utilizou-se uma codificação binária para a indicação da saída desejada da RNA para cada padrão de entrada (tabela 1).

Tabela 1: Esquema de codificação da saída desejada da RNA.

\begin{tabular}{ccccccc}
\hline \multirow{2}{*}{$\begin{array}{c}\text { Tipo de } \\
\text { Falta }\end{array}$} & Fases & \multirow{4}{*}{ Sigla } & \multicolumn{5}{c}{ Saídas } \\
\cline { 5 - 7 } & Envolvidas & Sig & S1 & S2 & S3 & S4 \\
\hline \multirow{3}{*}{ Monofásica } & A & AT & 1 & 0 & 0 & 1 \\
& B & BT & 0 & 1 & 0 & 1 \\
& C & CT & 0 & 0 & 1 & 1 \\
\hline \multirow{2}{*}{ Bifásica } & A e B & AB & 1 & 1 & 0 & 0 \\
& A e C & AC & 1 & 0 & 1 & 0 \\
& B e C & BC & 0 & 1 & 1 & 0 \\
\hline \multirow{2}{*}{ Bifásica } & A e B & ABT & 1 & 1 & 0 & 1 \\
para Terra & A e C & ACT & 1 & 0 & 1 & 1 \\
& B e C & BCT & 0 & 1 & 1 & 1 \\
\hline Trifásica & A, B e C & ABC & 1 & 1 & 1 & 0 \\
\hline
\end{tabular}

\section{IMPLEMENTAÇÃO DO MÉTODO PRO- POSTO}

$\mathrm{Na}$ implementação do método consideraram-se registros em LTs de 138, 230 e $500 \mathrm{kV}$ do sistema Chesf, capturados por RDPs de diferentes taxas de amostragem, como 5840 e $15360 \mathrm{~Hz}$. No entanto, para simular as faltas que foram incorporadas à base de dados da RNA, considerou-se a LT 04V4 (figura 5).

Utilizou-se o software ATP (Leuven EMTP Center, 1987) na simulação das faltas na LT 04V4, considerando-se os parâmetros do sistema distribuídos e independentes da freqüência (Brito et al., 2004). Construiu-se a base de dados considerando-se como variáveis: a localização, o ângulo de incidência e a resistência de falta (tabela 2). Ao total, foram simulados 360 registros.

O método proposto foi implementado na linguagem de programação C++, utilizando-se recursos de orientação a objetos. Em particular, as rotinas empregadas para o cálculo da TWD foram propostas por Press et al. (2003).

Avaliaram-se registros de diversos tipos de distúrbios, de forma que os valores de $C^{*}$ e $I_{m}$ foram escolhidos para cada nível de tensão (tabela 3). Dessa forma, pode-se distinguir a maioria dos registros de faltas daqueles relacionados aos distúrbios de QEE e às operações de manutenção do sistema. 


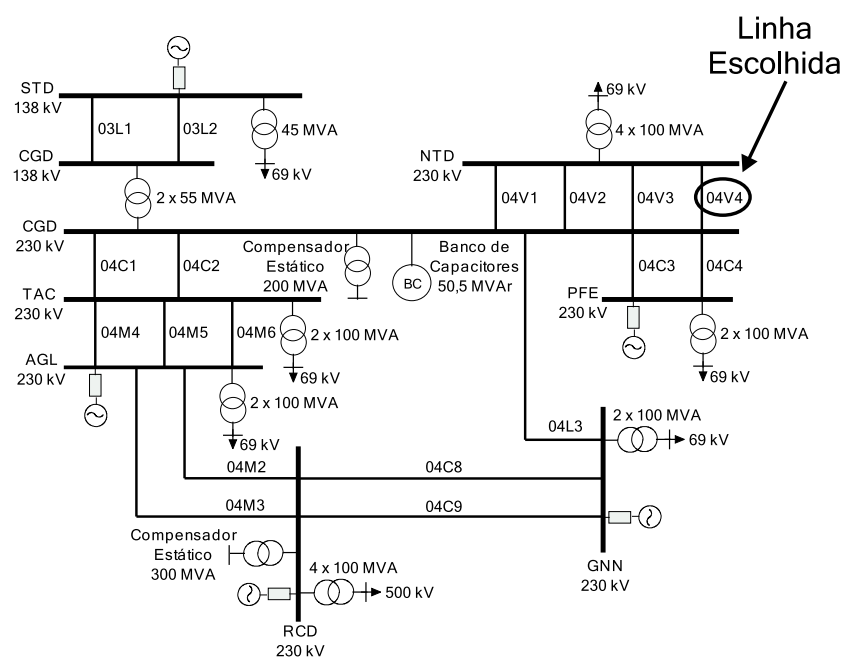

Figura 5: Representação simplificada do sistema analisado.

Tabela 2: Variáveis utilizadas na simulação da LT 04V4.

\begin{tabular}{cccc}
\hline $\begin{array}{c}\text { Variáveis de } \\
\text { Simulação }\end{array}$ & Treinamento & Validação & Teste \\
\hline \hline Locais de & $20-30-50$ & $10-70$ & $40-100$ \\
falta $(\mathrm{km})$ & $60-80-90$ & $130-160$ & $160-180$ \\
\hline Resistência & $110-120-140-150$ & & \\
de falta $(\Omega)$ & Fase-Fase: 1 e 10 \\
\hline Ângulo de & Fase-Terra: 50 e 100 & \\
Incidência $\left({ }^{\circ}\right)$ & 60 \\
\hline Tipos & AT-BT-CT-AB-AC-BC \\
de falta & ABT-ACT-BCT-ABC \\
\hline
\end{tabular}

Tabela 3: Valores de $C^{*}$ e $I_{m}$ para cada nível de tensão.

\begin{tabular}{ccc}
\hline $\begin{array}{c}\text { Nível de } \\
\text { Tensão }(\mathrm{kV})\end{array}$ & $C^{*}$ & $I_{m}(\mathrm{~A})$ \\
\hline \hline 138 & 10 & 40 \\
230 & 40 & 80 \\
500 & 70 & 120 \\
\hline
\end{tabular}

Para a geração de cada registro de falta simularam-se 3 ciclos de falta ( $3 \times 16,667 \mathrm{~ms})$, considerando-se uma freqüência de amostragem de $1200 \mathrm{~Hz}$ (20 amostras/ciclo). Portanto, cada registro possuía 60 amostras de falta (para cada sinal de corrente e tensão) em cada registro. Devido ao janelamento de 5 amostras consecutivas adotado, cada registro originou 56 janelas ou padrões de entrada para a RNA, resultando um total de 20160 padrões simulados, que foram distribuídos nos conjuntos de treinamento, validação e teste (tabela 4).
Para cada registro real, os processos de normalização, reamostragem e janelamento foram aplicados apenas ao intervalo de falta. Isso assegura padrões com freqüência de amostragem de $1200 \mathrm{~Hz}$, normalizados pelos máximos valores de tensão e corrente de cada registro, da mesma forma que os padrões simulados.

Registros reais diferentes foram incorporados aos conjuntos de treinamento, validação e teste, evitando-se que os mesmos padrões fossem adicionados a dois conjuntos distintos. Os padrões foram distribuídos conforme tabela 4.

Tabela 4: Distribuição dos padrões de entrada da RNA.

\begin{tabular}{cccc}
\hline \multirow{2}{*}{$\begin{array}{c}\text { Tipo } \\
\text { dos padrões }\end{array}$} & \multicolumn{3}{c}{ Número de padrões } \\
\cline { 2 - 4 } & Treinamento & Validação & Teste \\
\hline \hline Simulados & 11200 & 4480 & 4480 \\
Reais & 3316 & 2163 & 3928 \\
\hline & $\mathbf{1 4 5 1 6}$ & $\mathbf{6 6 4 3}$ & $\mathbf{8 4 0 8}$
\end{tabular}

Após vários testes, a melhor configuração da RNA encontrada possui 40 neurônios na camada de entrada, 30 neurônios na camada oculta e 4 neurônios na camada de saída. $\mathrm{O}$ tempo de treinamento foi de cerca de $49 \mathrm{~min}$, empregandose um PC $1.0 \mathrm{GHz}-384 \mathrm{Mb}$. O algoritmo empregado foi o RPROP (Riedmiller and Braun, 1993; Souza et al., 2004a). Foram necessárias 426 épocas de treinamento para atingir um erro médio quadrático de 0,02 para o conjunto de validação e $99,83 \%$ de acerto na classificação dos padrões do conjunto de teste.

\section{AVALIAÇÃO DO MÉTODO PROPOSTO}

O método proposto foi avaliado para registros oscilográficos reais e simulados. Além disso, descreve-se seu emprego na análise de diversos registros capturados devido à propagação dos efeitos de uma falta em uma LT de $500 \mathrm{kV}$ pelo sistema elétrico.

\subsection{Registros Simulados na LT 04V4}

Nessa avaliação, o software ATP foi utilizado para simular 720 registros de faltas (tabela 5), distintos dos que foram utilizados na fase de aprendizado da RNA. Cada um deles foi avaliado e obteve-se $100 \%$ de acerto na classificação do tipo de falta para todo o conjunto de registros.

\subsection{Registros Reais no Sistema Chesf}

O método proposto foi validado utilizando-se diversos registros com e sem distúrbios em diferentes LTs do sistema de transmissão da Chesf, capturados por RDPs com diferentes freqüências de amostragem. 
Tabela 5: Registros simulados para avaliação do método.

\begin{tabular}{cc}
\hline Variáveis de Simulação & Situações de Falta \\
\hline \hline Locais de falta $(\mathrm{km})$ & $10-20-\cdots-170-180$ \\
\hline Resistência de falta $(\Omega)$ & $\begin{array}{c}\text { Fase-Fase: 0,1 e } 5 \\
\text { Fase-Terra: } 30 \text { e } 80\end{array}$ \\
\hline $\begin{array}{c}\text { Ângulo de } \\
\text { Incidência }\left({ }^{\circ}\right)\end{array}$ & $30-120$ \\
\hline $\begin{array}{c}\text { Tipos } \\
\text { de falta }\end{array}$ & AT-BT-CT-AB-AC-BC \\
ABT-ACT-BCT-ABC \\
\hline
\end{tabular}

Tabela 6: Resultados para LTs de $500 \mathrm{kV}$.

\begin{tabular}{|c|c|c|c|}
\hline \multicolumn{2}{|c|}{ Diagnóstico } & \multirow{2}{*}{$\begin{array}{c}\mathrm{N}^{\mathrm{o}} \mathrm{de} \\
\text { Registros }\end{array}$} & \multirow{2}{*}{$\begin{array}{c}\text { Diagnósticos } \\
\text { Corretos }\end{array}$} \\
\hline Real & Esperado & & \\
\hline $\begin{array}{l}\text { Sem defeito } \\
\text { perceptível }\end{array}$ & Sem falta & 3 & 3 \\
\hline $\begin{array}{l}\text { Afundamentos } \\
\text { de tensão }\end{array}$ & Sem falta & 27 & 27 \\
\hline Transitórios & Sem falta & 2 & 2 \\
\hline $\begin{array}{l}\text { Desligamentos } \\
\text { de LTs }\end{array}$ & Sem falta & 2 & 2 \\
\hline $\begin{array}{c}\text { Energizações } \\
\text { de LTs }\end{array}$ & Sem falta & 1 & 1 \\
\hline Falta AT & Falta AT & 1 & 1 \\
\hline Falta BT & Falta BT & 5 & 5 \\
\hline Falta CT & Falta CT & 1 & 1 \\
\hline & & $\overline{42}$ & $\overline{42}$ \\
\hline
\end{tabular}

Atribui-se a indicação sem defeito perceptível àquele registro para o qual não existe identificação visual de distúrbio, mas mesmo assim foi registrado pelo RDP. Já os registros de transitórios oscilatórios são originados devido a manobras de chaveamento de bancos de capacitores e de compensadores estáticos. Enquanto as variações de carga são ocasionadas por desligamentos programados de elementos do sistema para sua manutenção ou para efeito de regulação do sistema.

A ocorrência de uma falta provoca um afundamento nas tensões do sistema, seguido por uma mudança na sua condição de operação depois da extinção da falta, ou seja, uma oscilação de sua carga. Dessa forma, grande parte dos registros de afundamentos de tensão contemplam também a variação da carga do sistema.

Os resultados para as LTs de 500, 230 e $138 \mathrm{kV}$ são apresentados nas tabelas 6,7 e 8 , respectivamente. A partir dos resultados obtidos, constatou-se que a escolha de diferentes limiares para cada nível de tensão proporcionou uma análise mais adequada dos registros analisados.
Tabela 7: Resultados para LTs de $230 \mathrm{kV}$.

\begin{tabular}{cccc}
\hline \multicolumn{2}{c}{ Diagnóstico } & $\begin{array}{c}\mathrm{N}^{\mathrm{o}} \text { de } \\
\text { Registros }\end{array}$ & $\begin{array}{c}\text { Diagnósticos } \\
\text { Corretos }\end{array}$ \\
\hline \hline $\begin{array}{c}\text { Sem defeito } \\
\text { perceptível }\end{array}$ & Sem falta & 213 & 213 \\
\hline $\begin{array}{c}\text { Variações } \\
\text { de carga }\end{array}$ & Sem falta & 24 & 24 \\
\hline $\begin{array}{c}\text { Afundamentos } \\
\text { de tensão }\end{array}$ & Sem falta & 156 & 156 \\
\hline Transitórios & Sem falta & 80 & 80 \\
\hline $\begin{array}{c}\text { Desligamentos } \\
\text { de LTs }\end{array}$ & Sem falta & 44 & 43 \\
\hline Energizações & Sem falta & 43 & 43 \\
de LTs & & & \\
\hline Falta AT & Falta AT & 4 & 3 \\
Falta BT & Falta BT & 15 & 14 \\
Falta CT & Falta CT & 13 & 13 \\
Falta AB & Falta AB & 1 & 1 \\
Falta BC & Falta BC & 1 & 1 \\
Falta ACT & Falta ACT & 1 & 1 \\
Falta BCT & Falta BCT & 2 & $\mathbf{5 9 3}$ \\
\hline & & $\mathbf{5 9 7}$ & \\
\hline
\end{tabular}

Tabela 8: Resultados para LTs de $138 \mathrm{kV}$.

\begin{tabular}{cccc}
\hline \multicolumn{2}{c}{ Diagnóstico } & $\begin{array}{c}\mathrm{N}^{0} \text { de } \\
\text { Registros }\end{array}$ & $\begin{array}{c}\text { Diagnósticos } \\
\text { Corretos }\end{array}$ \\
\hline $\begin{array}{c}\text { Sem defeito } \\
\text { perceptível }\end{array}$ & Sem falta & 184 & 184 \\
\cline { 1 - 2 } $\begin{array}{c}\text { Variações } \\
\text { de carga }\end{array}$ & Sem falta & 10 & 10 \\
\hline $\begin{array}{c}\text { Afundamentos } \\
\text { de tensão }\end{array}$ & Sem falta & 16 & 16 \\
\hline $\begin{array}{c}\text { Transitórios } \\
\text { Desligamentos } \\
\text { de LTs }\end{array}$ & Sem falta & 28 & 28 \\
\hline $\begin{array}{c}\text { Energizações falta } \\
\text { de LTs }\end{array}$ & Sem falta & 25 & 14 \\
\hline $\begin{array}{c}\text { Falta AT } \\
\text { Falta BT }\end{array}$ & Falta AT & 1 & 25 \\
Falta CT & Falta BT & 5 & 1 \\
\hline & 2 & $\mathbf{2 8 5}$ & 2 \\
\hline
\end{tabular}

Observou-se também que as regras para a determinação da duração da falta foram exatas na indicação do início da falta, mas em alguns casos foram imprecisas na indicação do seu fim. Com relação à classificação, obteve-se erro em alguns registros nos quais as condições de operação do sistema eram muito diferentes das consideradas na base de dados da RNA. 


\subsection{Estudo de caso}

Para avaliar a aplicabilidade do método proposto, apresentase a descrição de um estudo de caso relacionado à análise de registros oscilográficos capturados devido a ocorrência de uma falta monofásica do tipo CT, ocorrida na LT 05L9 de $500 \mathrm{kV}$ e $170 \mathrm{~km}$, localizada entre as SEs Angelim II (AGD) e Recife II (RCD) do subsistema Leste da Chesf (figura 6). A falta ocorreu à $87 \mathrm{~km}$ da SE AGD, devido a queimadas em plantações de cana-de-açúcar. Na figura 7 apresentam-se os sinais de tensão e corrente referentes à falta $\mathrm{CT}$, vistos do terminal de AGD.

Distúrbios relacionados a uma falta no sistema elétrico de potência são capturados por diversos RDPs circunvizinhos ao local do defeito. Dessa forma, além de analisar os registros da falta capturados pelos RDPs localizados nos terminais da LT 05L9, analisaram-se também os registros referentes às outras LTs próximas à LT 05L9.

Na figura 8 apresentam-se os sinais de tensão e corrente referentes ao RDP que monitora a LT 05L8, paralela à LT 05L9, instalado no terminal da SE AGD. Observa-se um afundamento da tensão e um aumento da corrente na fase $\mathrm{C}$ da LT 05L8, até o momento da extinção da falta. Em seguida observa-se que com a saída da LT defeituosa, o sistema passa para um novo estado de operação, no qual o fluxo de potência entre as SEs AGD e RCD é estabelecido apenas pela LT 05L8, provocando um aumento significativo da sua corrente com relação a seu valor de pré-falta. Esse mesmo comportamento é observado em outras LTs próximas à LT 05L9, até mesmo para aquelas com nível de tensão inferior à $500 \mathrm{kV}$.

Na tabela 9 são apresentados os resultados da análise de registros capturados por RDPs nas SEs AGD, RCD e Luis Gonzaga (LGZ) de 500 kV, e nas SEs Angelim (AGL), Tacaímbo (TAC) e CGD de $230 \mathrm{kV}$. Todos os RDPs possuem freqüência de amostragem de $15360 \mathrm{~Hz}$. Observa-se que o valor de $C_{\max }$ é inferior ao limiar $C^{*}$ para o registro da LT 05L8 e diminui gradativamente, à medida que os registros referem-se às LTs mais distantes do ponto de defeito (os transitórios oriundos da ocorrência da falta são amortecidos). Dessa forma, esses registros são diagnosticados como sem falta, conforme as regras apresentadas na Seção 2.1.1.

Com relação à indicação dos instantes inicial e final da falta, observa-se que o maior erro foi observado para o registro da falta capturado em AGD. Isso ocorreu devido a oscilações de alta freqüência observadas nas correntes das fases envolvidas na falta, originadas quando da atuação dos disjuntores para extinguir a falta. Essas oscilações se mantêm até a completa extinção do arco elétrico, que ocorre num período de tempo morto da ordem de 0,5 à 1,5 s (IEEE Power System Relaying Committee, 2003). Mesmo assim, a classificação da falta não foi comprometida.

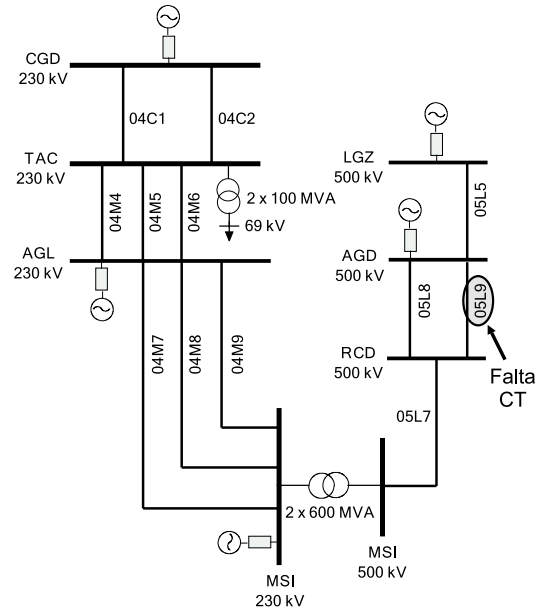

Figura 6: Sistema avaliado no estudo de caso.
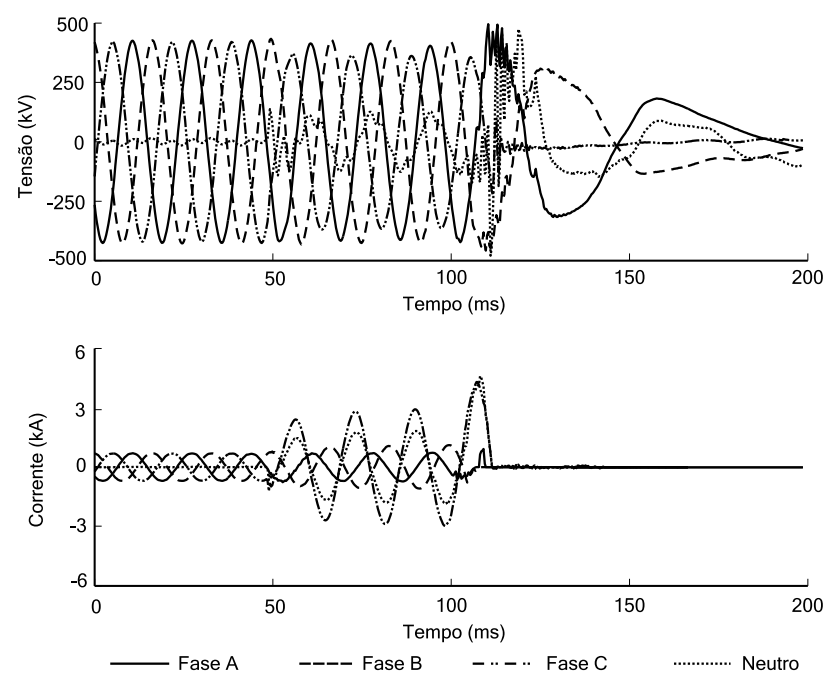

Figura 7: Registro da LT 05L9 visto do terminal AGD.
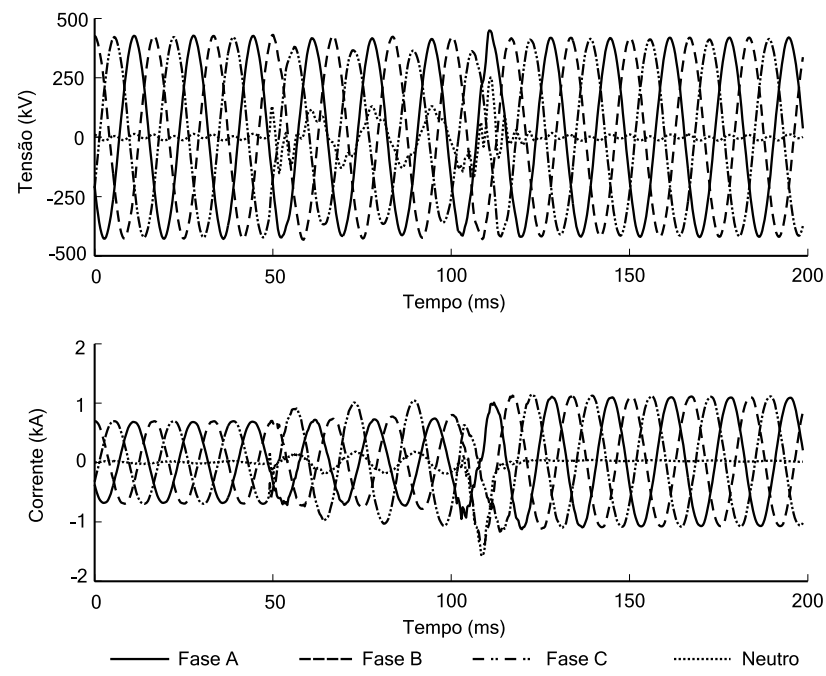

Figura 8: Registro da LT 05L8 visto do terminal AGD. 
Tabela 9: Resultados da análise dos registros capturados devido a uma falta CT na LT 05L9.

\begin{tabular}{|c|c|c|c|c|c|c|c|c|c|}
\hline \multirow{2}{*}{ LT } & \multirow{2}{*}{ Terminal } & \multirow{2}{*}{$\begin{array}{c}\text { Nivel de } \\
\text { Tensão }(k V)\end{array}$} & \multirow{2}{*}{$C_{\max }$} & \multirow{2}{*}{$I_{\text {pre }}(\mathrm{A})$} & \multirow{2}{*}{$I_{p o s}(\mathrm{~A})$} & \multirow{2}{*}{$\epsilon_{i}(\mathrm{~ms})$} & \multirow{2}{*}{$\epsilon_{f}(\mathrm{~ms})$} & \multicolumn{2}{|l|}{ Diagnóstico } \\
\hline & & & & & & & & Real & Obtido \\
\hline 05L9 & AGD & 500 & 114,9 & 696,7 & 12,4 & 0,7 & 8,1 & Falta CT & Falta CT \\
\hline 05L9 & $\mathrm{RCD}$ & 500 & 115,1 & 768,1 & 4,0 & 0,4 & 0,1 & Falta CT & Falta CT \\
\hline $05 \mathrm{~L} 8$ & AGD & 500 & 41,5 & 695,1 & 1102,5 & - & - & $\begin{array}{l}\text { Afundamento de Tensão } \\
\text { e Variação de Carga }\end{array}$ & Sem falta \\
\hline 05L5 & LGZ & 500 & 42,6 & 643,4 & 620,5 & - & - & $\begin{array}{l}\text { Afundamento de Tensão } \\
\text { e Variação de Carga }\end{array}$ & Sem falta \\
\hline 04M9 & AGL & 230 & 8,3 & 115,5 & 165,9 & - & - & $\begin{array}{l}\text { Afundamento de Tensão } \\
\text { e Variação de Carga }\end{array}$ & Sem falta \\
\hline 04M6 & TAC & 230 & 12,2 & 367,8 & 405,3 & - & - & $\begin{array}{l}\text { Afundamento de Tensão } \\
\text { e Variação de Carga }\end{array}$ & Sem falta \\
\hline $04 \mathrm{C} 1$ & CGD & 230 & 9,4 & 368,3 & 411,4 & - & - & $\begin{array}{l}\text { Afundamento de Tensão } \\
\text { e Variação de Carga }\end{array}$ & Sem falta \\
\hline
\end{tabular}

$\epsilon_{i}$ - Erro na indicação do instante inicial da falta.

$\epsilon_{f}$ - Erro na indicação do instante fi nal da falta.

\section{CONCLUSÕES}

Um método de deteç̧ão e classificação de faltas em LTs a partir da análise de registros oscilográficos foi apresentado e seu desempenho foi avaliado para o sistema de transmissão da Chesf. Resultados excelentes foram alcançados.

Ao contrário dos métodos já existentes, a principal contribuição do método proposto é a distinção de registros referentes à faltas de registros referentes a distúrbios relacionados à QEE e às manobras de manutenção e operação do sistema. Dessa forma, é possível realizar de forma eficiente uma triagem dos registros oscilográficos capturados pelos RDPs. Além disso, o método analisa registros oscilográficos reais de LTs de diversos níveis de tensão e topologias, capturados por RDPs com diferentes freqüências de amostragem.

Com relação às regras de detecção, apesar dos resultados evidenciarem uma possível generalização, estas não podem ser tidas como gerais. De fato, as regras se mostraram eficientes para os registros avaliados. No entanto, mais registros devem ser avaliados a fim de validar os limiares $C^{*}$ e $I_{m}$ empregados nesse artigo. Além disso, outras regras podem ser incorporadas ao método para torná-lo mais robusto.

O algoritmo de delimitação do intervalo de falta foi sempre bem sucedido na indicação da amostra inicial da falta, pois facilmente se identifica a mudança entre os intervalos de pré-falta e de falta. No entanto, em alguns registros reais, observa-se que até a extinção completa do defeito pelos dois terminais da LT, podem ocorrer alguns transitórios de alta freqüência nas correntes de fase, e, por conseguinte, na com- ponente de seqüência zero das correntes. Isso dificultou o processo de identificação do instante final da falta, ou seja, a transição entre os intervalos de falta e pós-falta, o que provocou erro do algoritmo proposto em cinco registros avaliados. Mesmo assim, a classificação da falta não foi comprometida.

\section{AGRADECIMENTOS}

Os autores agradecem ao CNPq pela concessão de bolsas de estudo e ao DPA/DOEM da Chesf, especialmente ao Dr. José Júlio A. L. Leitão e ao Sérgio G. A. Cauponi, pelo apoio técnico durante as pesquisas. O projeto a que se refere esse artigo foi financiado pelo Fundo Setorial de Energia, através do plano de P\&D da Chesf, ciclo 2000-2001.

\section{REFERÊNCIAS}

Brito, N. S. D., Neves, W. L. A., Souza, B. A., Dantas, K. M. C., Fontes, A. V., Costa, F. B., Fernades, A. B. and Silva, S. S. B. (2004). Influência do modelo de linhas de transmissão no diagnóstico de faltas, Transmission and Distribution Latin America Conf., São Paulo, Brasil.

Burrus, C. S., Ramesh, A. G. and Guo, H. (1998). Introduction to Wavelets and Wavelet Transforms, A Primer, Prentice Hall, New Jersey, USA.

Daubechies, I. (1992). Ten Lectures on Wavelets, CBMSNSF Regional Conference Series, Philadelphia, USA.

IEEE Power System Relaying Committee (1999). IEEE Standard Common Format for Transient Data exchange (COMTRADE) for Power Systems, IEEE, New York. 
IEEE Power System Relaying Committee (2003). IEEE Guide for Automatic Reclosing of Line Circuit Breakers for AC Distribution and Transmission Lines, IEEE Std C37.104-2002, New York, USA.

Kashyap, K. H. and Shenoy, U. J. (2003). Classification of power system faults using wavelet transforms and probabilistic neural networks, Proceedings of the 2003 International Symposium on Circuits and Systems, Bangkok, Tailândia.

Kezunovic, M. and Rikalo, I. (1996). Detect and classify transmission line faults using neural nets, IEEE Computer Applications in Power 9(4): 42-47.

Kezunovic, M. and Rikalo, I. (1999). Automating the analysis of faults and power quality, IEEE Computer Applications in Power 12(1): 46-50.

Kim, C. H. and Aggarwal, R. (2001). Wavelet transform in power system: Part 2 examples of aplication to actual power system transients, Power Engineering Journal pp. 193-202, August.

Leuven EMTP Center (1987). ATP - Alternative Transient Program - Rule Book, Herverlee, Belgium.

Mahanty, R. N. and Gupta, P. B. D. (2004). Application of rbf neural network to fault classification and location in transmission lines, IEE Proceedings of Generation, Transmission and Distribution 151(2).

Neves, W. L. A., Brito, N. S. D., Souza, B. A., Fontes, A. V., Dantas, K. M. C., Fernades, A. B. and Silva, S. S. B. (2004). Influência da freqüência de amostragem dos registradores digitais de perturbação no diagnóstico de faltas, Transmission and Distribution Latin America Conference, São Paulo, Brasil.

Oleskovicz, M., Coury, D. V. and Aggarwal, R. K. (2003). O emprego de redes neurais artificiais na detecção, classificação e localização de faltas em linhas de transmissão, SBA Controle \& Automação 14(02).

Pradhan, A. K., Routray, A., Pati, S. and Pradhan, D. K. (2004). Wavelet fuzzy combined approach for fault classification of a series-compensated transmission line, IEEE Transaction on Power Delivery 19(4).

Press, W. H., Teukolsky, S. A., Vetterling, W. T. and Flannery, B. P. (2003). Numerical recipes in $\mathrm{C}++$, Cambridge University Press.

Riedmiller, M. and Braun, H. (1993). A direct adaptive method for faster backpropagation learning: The rprop algorithm, Proceedings of the IEEE Int. Conf. on Neural Networks pp. 586-591, San Franscisco, USA.
Silva, K. M. (2005). Diagnóstico de faltas em linhas de transmissão baseado em redes neurais artificiais e transformada wavelet, Master's thesis, Universidade Federal de Campina Grande, Campina Grande, Brasil.

Solanki, M., Song, Y. H., Potts, S. and Perks, A. (2001). Transient protection of transmission line using wavelet transform, Developments in Power System Protection (479): 299-302.

Souza, B. A., Brito, N. S. D., Neves, W. L. A., Silva, K. M., Lima, R. V. and Silva, S. S. B. (2004a). Comparison between backpropagation and rprop algorithms to fault classification in transmission lines, International Joint Conference on Neural Networks, Budapeste, Hungria.

Souza, B. A., Brito, N. S. D., Silva, S. S. B., Silva, K. M., Costa, F. B. and Melo Filho, A. C. M. (2004b). Um classificador de faltas para análise de ocorrências no sistema Chesf, Congresso Brasileiro de Automática, Gramado, Brasil.

Vasilic, S. and Kezunovic, M. (2002). An improved neural network algorithm for classifying the transmission line faults, IEEE PES Winter Meeting, New York, USA.

Youssef, O. A. S. (2001). Fault classification based on wavelet transforms, Transmission and Distribution Conference and Exposition, Vol. 1, Atlanta, USA, pp. 531536.

Youssef, O. A. S. (2004). Combined fuzzy-logic waveletbased fault classification technique for power system relaying, IEEE Transactions on Power Delivery 19(2). 